\title{
8
}
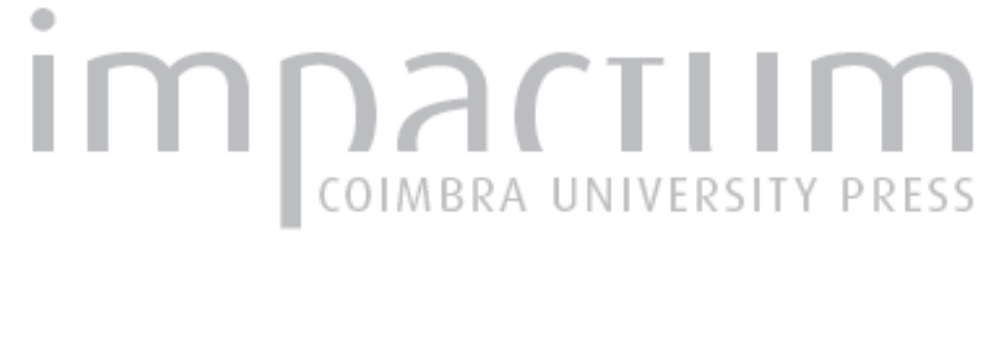

\section{Contextos educadores rumo à sustentabilidade: estudo de caso no município do} Fundão

\author{
Autor(es): $\quad$ Paredes, Liliana; Alcoforado, Luís; Cordeiro, A. M. Rochette
}

Publicado por: Imprensa da Universidade de Coimbra

URL persistente:

URI:http://hdl.handle.net/10316.2/36901

DOI:

DOI:http://dx.doi.org/10.14195/0871-1623_33_20

Accessed : $\quad$ 26-Apr-2023 08:33:59

A navegação consulta e descarregamento dos títulos inseridos nas Bibliotecas Digitais UC Digitalis, UC Pombalina e UC Impactum, pressupõem a aceitação plena e sem reservas dos Termos e Condições de Uso destas Bibliotecas Digitais, disponíveis em https://digitalis.uc.pt/pt-pt/termos.

Conforme exposto nos referidos Termos e Condições de Uso, o descarregamento de títulos de acesso restrito requer uma licença válida de autorização devendo o utilizador aceder ao(s) documento(s) a partir de um endereço de IP da instituição detentora da supramencionada licença.

Ao utilizador é apenas permitido o descarregamento para uso pessoal, pelo que o emprego do(s) título(s) descarregado(s) para outro fim, designadamente comercial, carece de autorização do respetivo autor ou editor da obra.

Na medida em que todas as obras da UC Digitalis se encontram protegidas pelo Código do Direito de Autor e Direitos Conexos e demais legislação aplicável, toda a cópia, parcial ou total, deste documento, nos casos em que é legalmente admitida, deverá conter ou fazer-se acompanhar por este aviso.

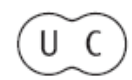




\section{Cadernos de Geografia}
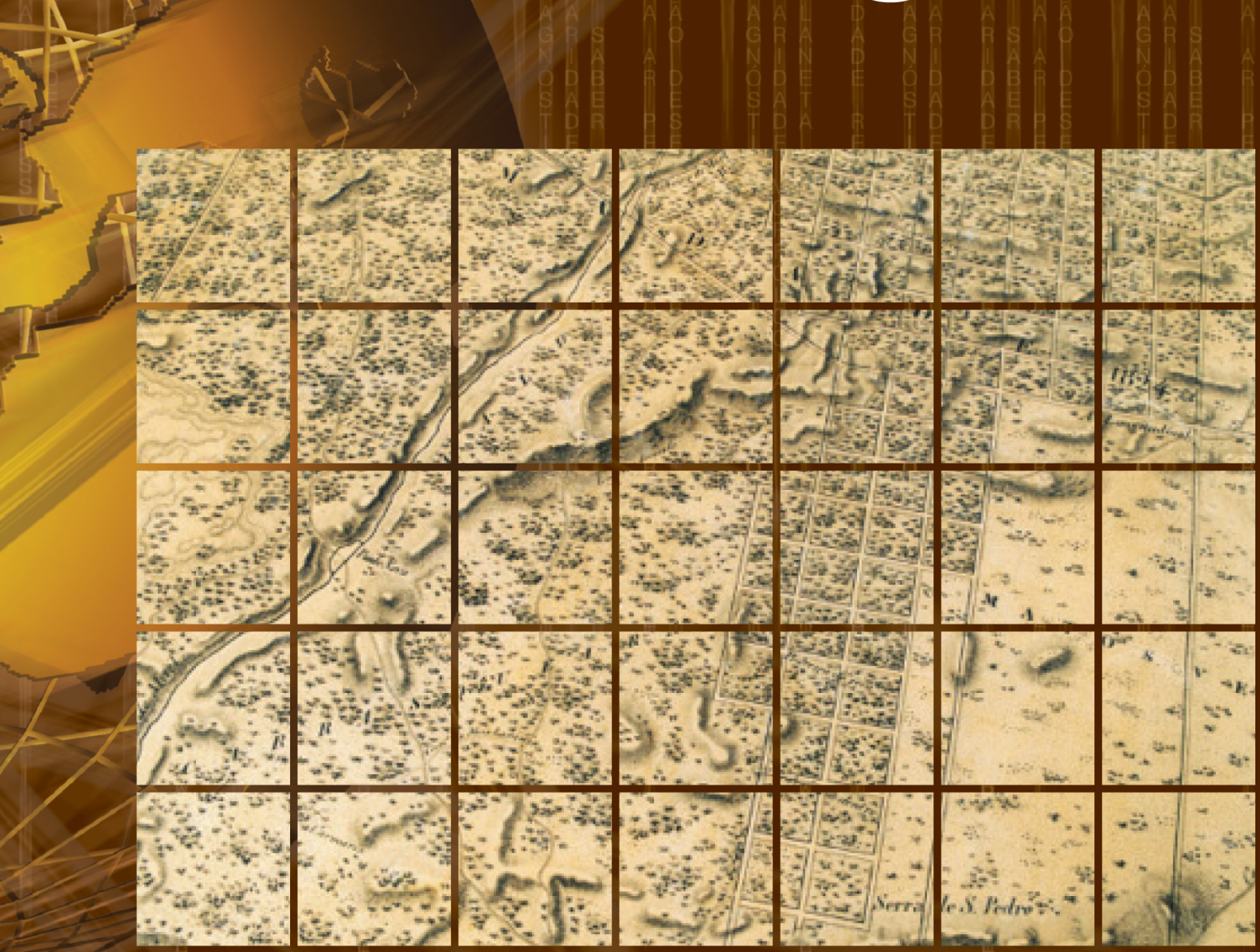

№ 33 - 2014

Imprensa da Universidade de Coimbra Faculdade de Letras | Universidade de Coimbra 


\title{
Contextos educadores rumo à sustentabilidade: estudo de caso no município do Fundão ${ }^{1}$ Educational contexts and sustainability: A case study of the Fundão municipality
}

\author{
Liliana Paredes \\ Doutoranda da Faculdade de Psicologia e Ciências da Educação. CEIS20. \\ lilianarparedes@gmail.com
}

\author{
Luís Alcoforado \\ Faculdade de Psicologia e Ciências da Educação. CEIS20. \\ lalcoforado@fpce.uc.pt
}

\section{A. M. Rochette Cordeiro}

Departamento de Geografia. Faculdade de Letras. Universidade de Coimbra e CEIS 20. rochettecordeiro@fl.uc.pt

\section{Introdução}

Os primeiros passos efetivos no sentido de fazer face aos novos desafios ambientais, decorrentes dos desafios impostos pela globalização do fenómeno da revolução industrial e pelas consequências dos dois conflitos bélicos mundiais, foram dados na década de 70 , e mais especificamente em 1972 com a realização da $1^{\text {a }}$ Conferência das Nações Unidas sobre o Meio Ambiente e o Desenvolvimento (SOROMENHO-MARQUES, 2004; Borrego, 2010; Freitas et al., 2012).

Cinco anos mais tarde, em 1977, realizou-se a $1^{\text {a }}$ Conferência Internacional de Educação Ambiental, responsável pela definição dos objetivos e princípios estratégicos da Educação Ambiental (BorRego, 2010; FreItAs et al., 2012).

Em 1987, no âmbito da Comissão Mundial sobre Ambiente e Desenvolvimento, são lançadas as bases para a definição do conceito de desenvolvimento sustentável, entendido como "o desenvolvimento que satisfaz as necessidades presentes, sem comprometer a capacidade das gerações futuras de suprir as suas próprias necessidades" (CMMAD, 1987). O grande passo foi o lançamento do relatório "Nosso Futuro Comum", no qual é efetuado um desafio e um apelo claro ao reequacionar dos padrões de produção e consumo que, até há data, continuavam a revelar-se incompatíveis com os padrões de desenvolvimento sustentável (SOROMENHO-MARQUES, 2004; Borrego, 2010; Paredes et al., 2013).

No decorrer do ano de 1992 é organizada no Rio de Janeiro, a Conferência das Nações Unidas sobre Ambiente e Desenvolvimento, na qual é definida um plano de ação com vista à criação de um novo padrão de desenvolvimento ambientalmente racional (BORREGo, 2010; FrEITAS et al., 2012) - a Agenda 21.

Em 2002, Joanesburgo serviu de palco à realização da Conferência Rio +10 , onde se firmou o compromisso com o desenvolvimento sustentável baseados em três pilares fundamentais: desenvolvimento económico, desenvolvimento social e proteção da natureza. Dez anos mais tarde, a Rio +20 , a Conferência das Nações Unidas sobre Desenvolvimento Sustentável realizada em junho de 2012, contou com a participação de 190 países e teve como principal objetivo a renovação do compromisso com o desenvolvimento sustentável, sendo que um dos temas em destaque foi o contributo da governança para a implementação de estratégias de sustentabilidade (Soromenho-Marques, 2004; Borrego, 2010).

Paralelamente, em Portugal, a década de 70 marcou o início da ascensão de uma nova consciência sobre a problemática ambiental e, desde então o conceito de desenvolvimento sustentável tem assumido uma importância crescente nos processos de planeamento e também nas estratégias pedagógicas associadas aos diferentes níveis de ensino. Desde então a evolução foi evidente, mas o caminho a percorrer ainda é longo e continuam a permanecer muitos dos desafios do passado (Borrego, 2010).

0 primeiro marco fundamental ao nível de uma crescente consciencialização sobre as problemáticas do ambiente e do desenvolvimento sustentável no nosso país foi a criação, através do decreto-lei 550/75 de 30 de Setembro, da Secretaria de Estado do Ambiente, sendo este organismo que, posteriormente, foi responsável pela reestruturação da Comissão Nacional do Ambiente.

$\mathrm{Na}$ sequência da adesão de Portugal à Comunidade Económica Europeia (CEE) em 1986, um ano mais tarde observa-se a publicação da Lei de Bases do Ambiente - Lei $n^{\circ} 11 / 87$ de 7 de Abril de 1987 . que teve um papel preponderante no desenvolvimento da política ambiental em Portugal (FreItAs et al., 2012). Esta diretiva assume que, por um lado, "todos os cidadãos têm direito a um ambiente humano e ecologicamente equilibrado (...), incumbindo ao Estado (...) promover a melhoria da qualidade de vida, quer individual, quer colectiva" e que, por outro, a "política de ambiente tem por fim optimizar e garantir a continuidade de utilização dos recursos

\footnotetext{
Este trabalho corresponde à comunicação, com o mesmo título, apresentada no VIII Colóquio de Geografia de Coimbra, subordinado ao tema "Espaço, Natureza e Sociedade. A Geografia na Estratégia 2020 da Região Centro", realizado na Faculdade de Letras da Universidade de Coimbra, nos dias 27 e 28 de março de 2014
} 
naturais (...) como pressuposto básico de um desenvolvimento auto-sustentado" (LEI DE BASES DO AMBIENTE, 1987:1386).

$01^{\circ}$ Plano Nacional de Política do Ambiente (1995), com um capítulo específico dedicado à temática da educação ambiental, preconizava a existência de uma articulação entre as políticas setoriais de ambiente, educação e formação, numa clara perspetiva de confluência de sinergias (PINTO, 2004).

Em termos curriculares, a reorganização do ensino básico, através do decreto-lei n 6/2001 de 18 de janeiro, e a reestruturação do ensino secundário, com o decreto-lei $n^{\circ} 113 / 2003$ de 4 de junho 2003, foram determinantes para a integração de três novas áreas não curriculares no caso do ensino básico - área de projeto, estudo acompanhado e formação cívica - e da integração de áreas curriculares não disciplinares no caso do ensino secundário. Esta reestruturação foi decisiva para que existisse uma maior abertura em termos dos próprios espaços educativos em relação a estas temáticas, contribuindo, ainda, até pelos pressupostos que estão inerentes ao desenvolvimento das atividades de educação ambiental, para uma crescente abertura da escola à comunidade e vice-versa, sendo esta responsável pelo sucesso das ações desenvolvidas no âmbito da educação ambiental em meio escolar.

No período compreendido entre o ano de 2000 e 2006, de salientar a aprovação da reestruturação do Instituto do Ambiente ${ }^{1}$ que passou a ter funções de coordenação na aplicação de políticas ambientais à escala regional e local e, ainda, a criação de um conjunto de políticas diretamente relacionadas com o ambiente e com o desenvolvimento sustentável, designadamente:

- Programa Polis (2000);

- PEAASAR I (2000-2006);

-Estratégia Nacional de Conservação da Natureza e Biodiversidade (2001);

- Estratégia Nacional de Desenvolvimento Sustentável (2002/2004/2006);

- Programa Nacional de Política de Ordenamento do Território (Lei n. ${ }^{\circ} 58 / 2007$, de 4 de Setembro);

- Novo Plano RIP-CIRVER (2003);

- Plano Nacional das Alterações Climáticas, (2002/2004/2006);

- Lei da Água (2005).

Neste contexto, a Resolução do Conselho de Ministros n. ${ }^{\circ} 152 / 2001$ de 11 de outubro define a Estratégia Nacional de Conservação da Natureza e da Biodiversidade. Esta foi determinante para uma crescente preocupação com as temáticas do ambiente e da sustentabilidade em Portugal, na medida em que enuncia como objetivos principais : 1) conservar a natureza e a diversidade biológica; 2) promover a utilização sustentável dos recursos; 3) contribuir para a prossecução dos objetivos internacionais em termos de conservação da natureza.

O IPAMB foi extinto em 2001, com consequente integração no Instituto do Ambiente (Dec. Lei $n^{\circ} 8 / 2002$ de 9 de Janeiro) e o Ministério do Ambiente e Ordenamento do Território foi substituído pelo Ministério das Cidades, Ordenamento do Território e Ambiente.
No período de 2007-2013 diversos fundos comunitários foram implementados (desenvolvimento rural, fundos estruturais), sendo de destacar a criação de um em particular, o LIFE+, cujo objetivo principal é contribuir para a execução, atualização e implementação de políticas e legislação ambientais nos países que integram a União Europeia.

Em 2008, e ao abrigo da Resolução do Conselho de Ministros $n^{\circ} 91 / 2008$ de 4 de Junho, verifica-se a entrada em vigor do Plano Nacional de Ação Ambiente e Saúde, ao abrigo de uma iniciativa conjunta dos Ministérios do Ambiente e do Ordenamento do Território e do Ministério da Saúde. Este plano segue as recomendações europeias e comunitárias no domínio do ambiente, designadamente no que diz respeito às orientações plasmadas no Plano de Ação Europeu Ambiente e Saúde 2004-2010 e ao Programa Comunitário de Ação em Matéria Ambiental. Por outro lado, veio permitir a criação de uma abordagem nacional, integrada e global em termos de ambiente e saúde, visando uma crescente compreensão das relações existentes entre os diferentes fatores ambientais e os possíveis efeitos na saúde. Finalmente, o Plano $\mathrm{Na}$ cional de Ação Ambiente e Saúde contempla os compromissos comunitários e internacionais assumidos por Portugal em matéria de ambiente e saúde.

Assumindo a importância que a participação dos cidadãos tem no sucesso das estratégias de consciencialização ambiental, encontra-se perfeitamente justificada a necessidade de desenvolvimento de programas/ações no âmbito da educação ambiental e do desenvolvimento sustentável que, direcionadas às camadas mais jovens da população, contribuam para a mudança de mentalidades, valores e comportamentos.

Em síntese, e ao longo de várias décadas foi possível observar uma crescente consciencialização de que as ações no domínio do ambiente e do desenvolvimento sustentável desempenham um papel crucial na modelação de comportamentos ambientalmente sustentáveis que, naturalmente, vão ter reflexos evidentes na preservação do património natural e na redução dos riscos de degradação ambiental.

\section{Novas perspetivas e desafios para a educação no século XXI}

Os desafios da sociedade atual ditam a necessidade de repensar o sistema educativo de forma mais abrangente e onde as diferentes dimensões do ambiente e do desenvolvimento sustentável se entrecruzam de forma a contribuir para uma sociedade mais consciente e alerta para a crescente degradação dos ecossistemas e, consequentemente, para a necessidade de preservação dos recursos naturais endógenos (Costa et al., 2000).

A maioria dos territórios enfrenta uma vasta panóplia de problemáticas quer ambientais, quer sociais, relacionadas com o estilo de vida e com os padrões de consumo, cujas consequências comprometem, inevitavelmente, a qualidade de vida dos cidadãos. Problemáticas como a degradação ambiental, o 
crescimento populacional, os processos de urbanização, a dispersão urbana, a degradação dos centros históricos, ou seja o "desordenamento", constituem algumas das problemáticas que, de forma mais ou menos evidente, afetam a generalidade dos territórios (CoRDEIRO et al., 2011). A resposta educativa à crise ambiental evoluiu no tempo à medida que as sociedades alteram a sua visão e conceito de ambiente (BARRACOSA et al., 2007).

A reflexão sobre o desafio ambiental no PEL (Cordeiro et al., 2011/12) e o seu papel na formação plena de alunos com consciência ecológica ditou a necessidade de desenvolver um contexto inovador em termos educativos, onde o planeamento de recursos e espaços vocacionados para a educação ambiental com base nas potencialidades endógenas se assume como uma peça fulcral (PAREDES et al., 2014).

Neste sentido, as ações definidas em sede de PEL e desenvolvidas no quadro local, pretendem amplificar o conceito de escola, chamando todos os agentes locais para participarem nestas ações e, do mesmo modo, "derrubar os muros da escola", criando as condições necessárias para que o território seja entendido como um verdadeiro agente educativo (Cordeiro et al., 2011/12; Paredes et al., 2014).

O conceito de "novas educações" deve, assim, ser encarado numa perspetiva de oposição à "educação atual”, tentando contrariar premissas pré-estabelecidas como sejam, a educação termina com a entrada na vida ativa, o território é visto como um simples recursos pedagógico da escola e, na maioria das vezes, existe um distanciamento entre esta e os recursos do meio (Cordeiro et al., 2011/12). É certo que este conceito acarreta um conjunto de desafios que se traduzem em duas questões fundamentais: será que este conceito, tal como Justino (2010) questiona, se traduz em mais educação ou melhor educação? Além disso, e considerando que esta "nova educação" implica necessariamente mais e melhor educação, estaremos em condições de capacitar os agentes educativos no sentido de dar resposta aos novos desafios impostos pela amplificação do espaço educativo?

Naturalmente, estes desafios traduzem-se, em contexto local, pela integração da formação ao longo e em todos os espaços da vida (Alcoforado, 2008), pela necessidade do processo educativo se desenvolver no quadro territorial, já que o território passa a ser entendido como gerador de oportunidades educativas e gerador de conflitos organizadores dos processos educativos e, ainda, pela perceção de que o território é, em si mesmo, um verdadeiro agente educativo (Figura 1).

Neste contexto, parece-nos essencial que a educação formal seja complementada com práticas de educação não formal e informal, considerando que existe uma necessidade de formação ao longo e em todos os espaços da vida (AlCOFORADo, 2008; CorDEIRO et al., 2011/12).

Esta necessidade encontra-se patente, entre outras, na oferta educativa/formativa direcionada à temática ambiental e ao desenvolvimento sustentável que, naturalmente, reflete muitas das lacunas existentes em termos curriculares. Esta oferta, em- bora redutora, encontra-se também enquadrada nos diferentes projetos educativos das escolas, com atividades, cursos e projetos que refletem a relação entre a escola e o meio e que, em muitos casos, estão na base do que se pretende para o PEL - uma crescente "educação territorial sustentável" ou, de forma mais sucinta - um ecodesenvolvimento, onde devem estar plasmados os eixos básicos da pedagogia ambiental, designadamente "aprender a conhecer", "aprender a fazer", "aprender a viver" e "aprender a ser” (SACHS, 1986; JACOBI, 2003; RodRIguez et al., 2009; VIEIRA, 2009).

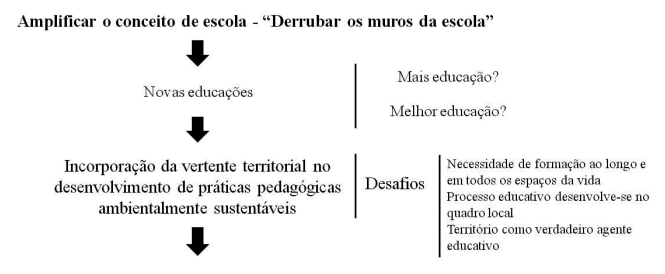

Estaremos em condições de capacitar os agentes

educativos para dar resposta a estes novos desafios?

Figura 1

Novas perspetivas para a educação no século XXI.

Fonte: Justino, 2010; Cordeiro et al., 2012.

A “territorialização da educação", ao traduzir-se na formalização da participação da comunidade na ação educativa através dos atores individuais e coletivos, tem em consideração as problemáticas relacionadas com o estilo de vida e com os novos padrões de consumo. Neste sentido, o envolvimento e participação dos cidadãos nos processos de decisão contribui para uma cidadania efetiva e corresponsável e em consonância uma sociedade que, crescentemente, funciona em rede (FonseCA et al., 2010).

Será então esta nova e desafiante abordagem que irá contribuir para o reequacionar do papel da educação e dos próprios agentes educativos, numa lógica de desenvolvimento e melhoria da qualidade de vida individual e comunitária (CORDEIRo et al., 2011/12).

O cruzamento das dimensões do ambiente e do desenvolvimento sustentável e a sua necessária articulação com os recursos endógenos do território permite a definição de paisagens educativas e de territórios educadores que, a posteriori, se irão traduzir no desenvolvimento sustentável de um território, referenciado por SACHS (1986), JACOBI (2003) e Rodriguez et al. (2009) como ecodesenvolvimento. Assim, pode afirmar-se que o ecodesenvolvimento diz respeito ao desenvolvimento de um território, analisado a diferentes escalas e consistente com as potencialidades da área envolvente. Neste caso é colocada a tónica no uso racional e adequado dos recursos naturais, tecnológicos e formas de organização, em suma, uma visão integrada do ambiente e do desenvolvimento (Glossary of Environment StatisTICS, 1997).

Todavia, o processo de definição de territórios educadores apenas será possível e exequível se o sistema educativo for equacionado numa perspetiva 
mais alargada. Assim, é indispensável que o processo educativo se desenvolva no quadro local, sendo que para atingir este objetivo, além da congregação de sinergias entre os diferentes parceiros educativos, é necessária a concentração de inúmeras valências educativas (espaços e recursos). 0 objetivo central é envolver todos os parceiros educativos nesta praxis transformadora, aproximando as práticas pedagógicas tradicionais (educação formal) aos novos paradigmas de práticas educativas (educação não formal e informal) e, neste sentido, promover uma coexistência pacífica (Alcoforado, 2008; VIEIRA, 2009; VAsConcelos, 2010).

Neste contexto, torna-se fundamental articular práticas pedagógicas sustentáveis que contribuam para a conceção de uma abordagem inovadora do ambiente e da sustentabilidade em contexto escolar e extra-escolar, em que a oferta formal deverá ser complementada com atividades de educação não formal e informal, essencialmente vocacionadas para as primeiras etapas da educação básica.

\section{Ambiente e desenvolvimento sustentável nas} primeiras etapas da educação básica: orientações pedagógicas e metas curriculares

No âmbito da educação pré-escolar, e uma vez que o objetivo final é identificar a necessidade de criação de atividades ecoformativas no domínio do ambiente direcionadas às primeiras etapas da educação básica, é fundamental apontar os objetivos que norteiam as orientações pedagógicas deste nível de ensino. Neste sentido, foi possível identificar objetivos fundamentais que, posteriormente, serão essenciais para a prossecução das aprendizagens no contexto de todas as áreas conteúdo, em geral, e no domínio do ambiente, em particular (MINISTÉRIO DA EduCAÇÃo, 1997).

Deste modo, e no que à educação pré-escolar diz respeito, o desenvolvimento e aprendizagem devem ser vistas como vertentes indissociáveis nos processos educativos. Por outro lado, a criança deve ser reconhecida como um agente educativo, devendo ter um papel interventivo em todo o processo, o que, naturalmente, estará também dependente da intencionalidade educativa dos educadores, os quais devem ter como preocupação central a construção articulada do saber e das aprendizagens. Neste sentido, o sucesso destas aprendizagens está obviamente dependente da procura de respostas por parte de todas as crianças, na medida em que estas devem ter um papel crescentemente interventivo no processo educativo, podendo mesmo tecer algumas considerações sobre os conteúdos a abordar.

As orientações pedagógicas na educação pré-escolar encontram-se organizadas em três áreas conteúdo, designadamente formação pessoal e social, conhecimento do mundo e expressão/comunicação. Da análise efetuada foi possível identificar que apenas nas áreas conteúdo formação pessoal e social e conhecimento do mundo são abordadas temáticas no domínio do ambiente e da sustentabilidade, sendo que a área conteúdo "expressão/ comunicação" surge apenas numa lógica de complementaridade às aprendizagens realizadas nas restantes áreas (Figura 2 ).

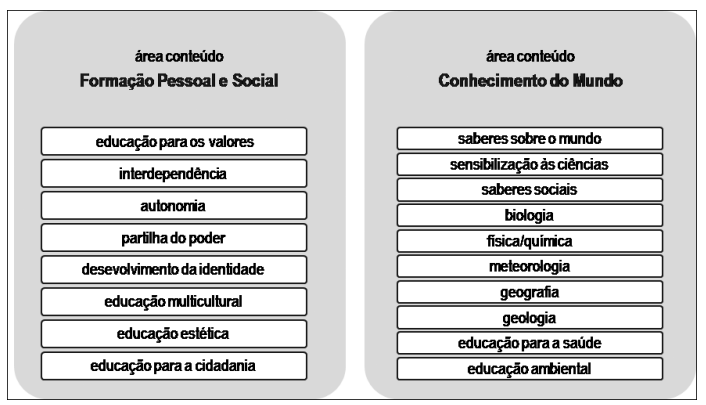

Figura 2

Ambiente e sustentabilidade nas orientações pedagógicas da educação pré-escolar.

Fonte: Ministério da Educação, 1997.

Relativamente ao $1^{\circ}$ CEB os pressupostos que devem estar na base das orientações curriculares vocacionadas para este nível de ensino (Ministério da Educação, 2004) são:

- Criar condições para o desenvolvimento global e harmonioso da personalidade;

- Proporcionar a aquisição e domínio de saberes, instrumentos, capacidades, atitudes e valores;

- Desenvolver valores/atitudes/práticas que contribuam para a formação de cidadãos conscientes e participativos.

Partindo destes pressupostos, as questões relacionadas com o ambiente e a sustentabilidade no âmbito do $1^{\circ}$ Ciclo do Ensino Básico são abordadas no contexto da disciplina de Estudo do Meio e mais especificamente em três dos seis blocos que a integram (Figura 3), designadamente "à descoberta do meio natural", "à descoberta dos objetos e materiais" e "à descoberta das inter-relações entre a natureza e a sociedade".

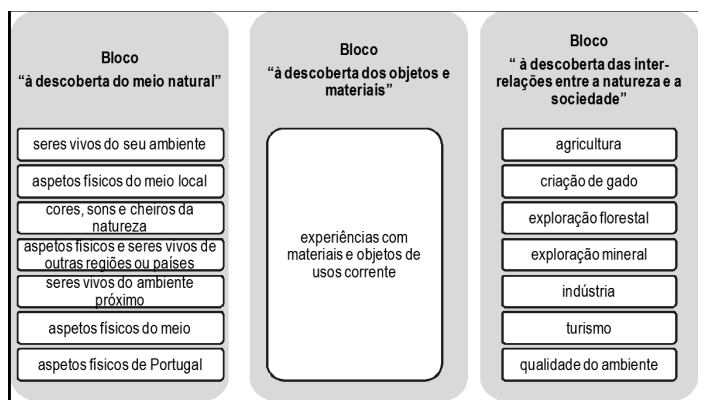

Figura 3

Ambiente e sustentabilidade nas orientações pedagógicas do $1^{\circ} \mathrm{Ciclo}$ do Ensino Básico.

Fonte: Ministério da Educação, 2004. 
Ambiente e desenvolvimento sustentável no PEL: o caso do município do Fundão

Por se tratar de um instrumento estratégico no contexto educativo municipal, o PEL não pode deixar de contemplar o ambiente e o desenvolvimento sustentável como áreas prioritárias de intervenção pelo seu papel na modelação de comportamentos compatíveis com a formação de sociedades sustentáveis (ARrotela, 2008).

A amplificação do conceito de escola e a reafirmação do conceito de "novas educações", levou-nos a questionar se estas estratégias implicam mais educação e, acima de tudo, melhor educação (JusTINo, 2010). O grande desafio parece estar na capacitação dos agentes educativos para fazer face aos novos exigências da educação do século XXI, especificamente no que se refere à incorporação da vertente territorial no desenvolvimento de práticas pedagógicas ambientalmente sustentáveis.

Naturalmente, para dar resposta a este desafio o primeiro passo consiste precisamente na elaboração de uma diagnóstico que nos permita antever as reais necessidades dos diferentes agentes educativos. Este diagnóstico deve centrar-se em três variáveis fundamentais, designadamente agentes educativos envolvidos - crianças/alunos, salas de atividade/aula, educadores/professores -, espaços e recursos - espaços naturais, produtos, rotas, percursos - e, ainda, práticas atualmente implementadas no estabelecimento de educação/ensino - materiais pedagógicos, projeto educativo da escola, conteúdos curriculares e conteúdos extracurriculares.

A análise conjunta destas variáveis vai permitir- nos aferir quais as necessidades em termos de ecoformação para um dado território e, paralelamente, delinear uma estratégia, em estreita colaboração com educadores/professores. O diagnóstico elaborado para o caso do território do município do Fundão permite-nos responder a três questões fundamentais, considerando a realidade municipal:

1) Que conteúdos?

- Importância da floresta e dos ecossistemas florestais;

- O clima e a sua relação com o ambiente urbano e a poluição;

- Tratamento dos resíduos (separação, valorização orgânica, valorização energética;...);

- Ciclo de vida dos materiais;

- Valorização da compostagem;

- Hortas pedagógicas;

- Recursos hídricos;

- Fauna e flora.

2) Que áreas/locais prioritários?

- Vale do Zêzere (elevado interesse ambiental);

- $\quad$ Serra da Gardunha - Rede Natura 2000 (Diretiva Habitat Gardunha),

- Ribeira da Meimoa;

- Geopark Naturtejo;

- $\quad$ Aldeias de Xisto (Janeiro de Cima e Barroca);

- Centro de Interpretação de Arte Rupestre.
3) Que formas de atuação?

- Participação em atividades ambientais diversas;

- Participação em projetos relacionados com a sustentabilidade;

- Alargar o número de clubes escolares associados à temática do ambiente;

- Planificação de materiais e recursos ecoformativos - aproveitamento dos recursos naturais endógenos, melhorando o conhecimento do território envolvente;

- Incremento de ações de formação para professores - ferramentas necessárias para um maior conhecimento do território em que se inserem e, do mesmo, modo, criar os mecanismos necessários para que a sua prática pedagógica vá de encontro às necessidades e expetativas dos alunos;

- Ações de (in)formação em contexto - direcionadas, numa primeira fase, a professores, permitindo a passagem dos conhecimentos adquiridos pelos professores aos seus alunos).

É, pois, o resultado da congregação de todas estas sinergias que vão conduzir à concretização da amplificação do conceito de espaço educativo e à elaboração de atividades/ações/materiais que, com base nos recursos territoriais locais, alertem os mais jovens para a necessidade de preservação do ambiente, sendo que esta estratégia será tanto mais conseguida quanto mais estes conhecerem as potencialidades naturais do território no qual se inserem (Figueiredo et al., 2014).

Deste modo, é evidente a necessidade de fornecer aos nossos jovens as ferramentas e mecanismos adequados para que estes possam contribuir para a promoção dos recursos naturais do seu território (Pereira, 2009), atitude que será determinante para mudar os comportamentos e atitudes face à preservação do ambiente de forma global.

Evidentemente, estas mudanças, em contexto formal e não formal, passam essencialmente pelo desenvolvimento e implementação de ações de formação de professores, sendo esta uma das medidas no âmbito da implementação do PEL do município do Fundão, que vai avançar a curto prazo. Assim, e neste contexto específico, o papel do professor, enquanto principal interveniente na ação educativa, deverá ser equacionado, essencialmente, numa lógica de "criação de cidadãos ativos e críticos, colocando o enfoque nas práticas educativas disciplinares, com atividades mais abertas e partilhadas" (FIGUEIREDo et al., 2014: 3831)

Neste sentido, estão previstas ações de formação dirigidas aos diretores de agrupamento e aos professores cuja duração prevista será entre 25 a 50 horas (mediante a disponibilidade dos docentes). Pretende-se que o trabalho com os diretores de agrupamento tenha consequências ao nível do projeto educativo do agrupamento, designadamente com a integração, desenvolvimento e valorização dos conceitos subjacentes ao PEL, designadamente, ci- 
dadania, democracia participativa, sustentabilidade, ecoterritório, entre outros.

Por outro lado, as ações de formação equacionadas para os professores têm como objetivos fundamentais: 1) envolver os professores na exploração do território local; 2) dar a conhecer diferentes estratégias pedagógicas de exploração do território no âmbito dos conteúdos curriculares e extracurriculares; 3) contribuir para a construção de um portefólio de materiais didáticos e pedagógicos que incidam sobre o território e respetivos recursos endógenos. Trata-se, assim, de habilitar os agentes educativos, designadamente os professores, para a criação de recursos didáticos que explorem os recursos do território do Fundão, considerando que o seu território é um espaço de aprendizagem por excelência.

\section{Notas conclusivas}

Este é um século de constantes e crescentes desafios ambientais e onde a educação ambiental e educação para o desenvolvimento sustentável poderão desempenhar um papel de destaque na compreensão e até mesmo na tentativa de resolução da crise sócio-ambiental.

De forma global, o grande desafio a que a escola e demais espaços educativos têm que responder nos dias de hoje relaciona-se com a necessidade de envolver todas as crianças e jovens, durante muito mais tempo e ensinar-lhes muitas mais coisas, assumindo-se, também, a necessidade de prolongar as experiências educativas ao longo e em todos os espaços da vida.

Um dos grandes desafios do PEL é colocar a tónica no vetor ambiente como fator de desenvolvimento sustentável do território, potenciando o conhecimento desse mesmo território por parte dos cidadãos mais jovens, sendo que a aquisição desse conhecimento apenas será possível com estratégias direcionadas a outros agentes educativos, designadamente os docentes.

Como estratégia fundamental destaca-se que todo o trabalho de desenho e implementação das atividades inerentes ao vetor ambiente do PEL (assim como em todos os outros vetores considerados estratégicos) deve ser realizado de forma participada por todos os agentes intervenientes no sistema educativo o que, necessariamente, irá conduzir a uma amplificação do conceito de espaço educativo, sendo este inquestionável no novo modelo de escola para o século XXI.

O PEL do município do Fundão pretende ser um parceiro privilegiado da comunidade escolar. Neste sentido, as ações equacionadas neste âmbito, designadamente no que diz respeito à partilha de saberes e experiências nos domínios do ambiente e do desenvolvimento sustentável, visam a definição de ações, materiais e recursos ecoformativos com vista à criação de ecocidadãos e, consequentemente, de ecoterritórios.

$\mathrm{Na}$ atual visão de sustentabilidade para o município do Fundão, onde as vocações ambientais e turísticas apresentam um peso decisivo, entende-se que a abertura dos estabelecimentos de ensino a novas propostas de ecoformação contribui para a formação de cidadãos cada vez mais conscientes e capazes de interiorizar os conceitos de sustentabilidade, ética, humanismo, cidadania e colaboração. Portanto, somente juntando e acumulando sinergias ao longo de todo o percurso escolar se poderá proporcionar às crianças e jovens um ambiente de aprendizagem inovador, motivador, exigente e gratificante.

Em síntese, o município do Fundão, ao entender o PEL como um dos documentos estruturantes no domínio educativo, pretende dar respostas aos seus cidadãos e demais agentes educativos, no sentido de procurar sinergias que apoiem o reforço das competências pedagógicas com base no território. Procuramos com este trabalho, por um lado, motivar e cativar professores e alunos para as problemáticas do ambiente e do desenvolvimento sustentável e, por outro lado, contribuir de forma inequívoca para a criação de um estreito vínculo entre estes e o seu território, porque efetivamente "só se ama o que se conhece".

\section{Bibliografia}

Alcoforado, Luís (2008) - Competências, Cidadania e Profis sionalidade: limites e desafios para a construção de um modelo português de Educação e Formação de Adultos. Tese de Doutoramento apresentada à Universidade de Coimbra - Não publicada, Coimbra

ARrotelA, Jorge (2008) - Educação e Desenvolvimento: fundamentos e conceitos. Theoria Poeisis Praxis, Universidade de Aveiro, $391 \mathrm{p}$.

Barracosa, Helena e Cartea, Pablo (2007) - “Actividades realizadas pelos Equipamentos para a Educação Ambiental em Portugal: uma aproximação mediante análise estatística de dados textuais". Atas do I Congreso Internacional de Educatión Ambiental dos Países Lusófonos e Galicia, Universidade da Coruña e a Universidade de Santiago de Compostela, Santiago de Compostela.

Borrego, Carlos (2010) - "A política ambiental de Portugal no espaço europeu: atitudes e desafios”. Europa: Novas Fronteiras Portugal: 25 anos de integração europeia, $\mathrm{n}^{\circ}$ 26/27 (Jan./Dez. 2010), Centro de Informação Europeia Jacques Delors,. pp. 177-182.

Comissão Mundial sobre Meio Ambiente e Desenvolvimento (1987) Relatório Bruntland - Nosso Futuro Comum, ONU.

Cordeiro, A. M. Rochette; Alcoforado, Luís e Ferreira, António Gomes (2011/12) - "Projeto Educativo Local. Um Processo Associado a Estratégias de Desenvolvimento Integrado e Sustentável". Cadernos de Geografia. DG-FLUC, Coimbra, pp. 313-324.

Cordeiro, A. M. Rochette e Barros, Cristina (2011) - Uma cidade sustentável, um território coeso: o exemplo da 
Figueira da Foz. Filosofia de um projeto integrado de planeamento e ordenamento do território. Atas do $17^{\circ}$ Congresso da APDR e $5^{\circ}$ Congresso de Gestão e Conservação da Natureza - Gestão de Bens e Desenvolvimento Regional Sustentável, Bragança - Zamora, pp. 1336-1345.

Costa, Francisco Silva e Gonçalves, António Bento (2000) "Educação ambiental e cidadania: Os desafios da escola de hoje". Actas dos ateliers do Vo Congresso Português de Sociologia, Sociedades Contemporâneas: Reflexividade e Acção - Atelier: Ambiente, Departamento de Geografia, Instituto de Ciências Sociais da Universidade do Minho, Portugal, pp. 33-40.

Decreto-lei n. ${ }^{\circ} 17 / 2014$ - Diário da República, $1 .^{a}$ série, $n .{ }^{\circ}$ 24 de 4 de fevereiro de 2014.

Decreto-lei n 113/2003 - Diário da República - Série I-A, n. 129 de 4 de Junho de 2003.

Decreto-lei n. ${ }^{\circ}$ 6/2001 - Diário da República - I Série-A, n. ${ }^{\circ}$ 15 de 18 de Janeiro de 2001.

Decreto-lei n. ${ }^{\circ}$ 550/75 - Diário da República - Série I, n. ${ }^{\circ} 226$ de 30 de Setembro de 1975.

Despacho normativo n. ${ }^{\circ}$ 13-A/2012 - Diário da República, 2. ${ }^{\mathrm{a}}$ série, $n .^{\circ} 109$ de 5 de junho de 2012.

Figueiredo, Patrícia; Cordeiro, A. M. Rochette; Alcoforado, Luís e SAntos, Lúcia (2014) - “O Papel dos Professores nos Projetos Educativos Locais: testemunho de uma reflexão conjunta em dois municípios da região centro de Portugal". Atas do II Congresso Luso-brasileiro Trabalho Docente e Formação Políticas, Práticas e Investigação: pontes para a mudança, Universidade do Porto, pp. 3831-3842.

FreitAs, Helena e Martins, Maria João (2012) - "Debater a Europa”. Periódico do CIEDA e do CEIS20, N.7 Julho/ Dezembro 2012 - Semestral, Disponível: http://www. europe-direct-aveiro.aeva.eu/debatereuropa/ acedido em 10 de março de 2014.

Glossary of Environment Statistics (1997) - Studies in Methods, Series F, $N^{\circ}$ 67, United Nations, New York.

Justino, David (2010) - Difícil é educá-los. Fundação Manuel Francisco dos Santos, Lisboa

Louro, Paulo e Fernandes, Pedro Aires (2004) - A intervenção autárquica no campo educativo: Estudo de caso num Município da Área Metropolitana de Lisboa. Análise Psicológica, Volume 1, $\mathrm{n}^{\circ}$ XXII, ISPA, pp. 273-287.

MINISTÉRIO dA EdUCAÇão (1997) - “Orientações curriculares para a educação pré-escolar” Departamento de Educação Básica - Gabinete para a expansão e desenvolvimento da Educação Pré-escolar, Lisboa.

MinistÉRIO dA EducAÇão (2004) - Programas e metas curriculares do Ensino Básico (http://dge.mec.pt/metascurriculares/ index.php?s=directorio\&pid=2 [10 de março de 2014].
Paredes, Liliana; Alcoforado, Luís e Cordeiro, A. M. Rochette (2013) - “Implementação do "centro cívico-educativo" da ilha da Morraceira: bases para a territorialização da educação na Figueira da Foz", Atas do IX Congresso da Geografia Portuguesa - Geografia: Espaço, Natureza, Sociedade e Ciência, Universidade de Évora, pp. 612-617.

Paredes, Liliana; Cordeiro, A. M. Rochette e Marques, David (2013) - “O vetor ambiente em projetos estratégicos: da educação e formação ao desenvolvimento sustentado em lógicas de competitividade territorial". Atas do $19^{\circ}$ Congresso da APDR, Políticas de Base Regional e Recuperação Económica. Universidade do Minho, pp. 1112-1021.

Paredes, Liliana; Alcoforado, Luís e Cordeiro, A. M. Rochette (2014) - “O ambiente como dimensão estruturante do Projeto Educativo Local: novos desafios para as Escolas e para os Professores". Atas do II Congresso Luso-brasileiro Trabalho Docente e Formação Políticas, Práticas e Investigação: pontes para a mudança, Universidade do Porto, pp. 2970-2982.

Pereira, Rosa (2009) - Educação Ambiental no Ensino Básico e Secundário: concepção de professores e análise de manuais escolares, Dissertação de Doutoramento no Ramo de Estudos da Criança, Área de Conhecimento Estudo do Meio Físico, Universidade do Minho.

Pınto, Joaquim (2004) - Educação Ambiental em Portugal: Raízes, influências, protagonistas e principais acções. Educação, Sociedade \& Culturas, $\mathrm{n}^{\circ} 21$, Porto, pp. 151-165.

Santos, Luís Filipe (2009) - O Projecto Educativo Local numa “Cidade Educadora": dos princípios às práticas. Dissertação de mestrado não publicada, Universidade de Aveiro.

Soromenho-Marques, Viriato (2004) - “Economia, Política e Desenvolvimento Sustentável. Os Desafios da Crise Global e Social do Ambiente", Educação, Sociedade \& Culturas, , $\mathrm{n}^{\circ} 21$, Porto, pp. 9-22.

TRISTÃo, Martha (2004) - A educação ambiental na formação de professores: redes de saberes, Annablume, Vitória, São Paulo, 236 p.

VASCONCELOS, Lia (2010) - “Comunicar ambiente em ciência e tecnologia”. In: Fonseca, Rui; Vasconcelos, Lia; Alho, José e Lopes Maria (Org.) - Ambiente, Ciência e Cidadãos, Esfera do Caos, Lisboa, pp. 9-16.

Vieıra, Flávia (2009) - "Para uma visão transformadora da supervisão pedagógica”. Educ. Soc., Campinas, [online] vol. 29, n 105, pp. 197-217, jan./abr, Disponível: http://www.cedes.unicamp.br [2 de Maio de 2014]. 